\title{
Modeling of a stair-climbing wheelchair mechanism with high single step capability
}

\author{
Murray J Lawn, Member, IEEE, and Takakazu Ishimatsu
}

\begin{abstract}
In the field of providing mobility for the elderly and disabled the aspect of dealing with stairs continues largely unresolved. This paper focuses on presenting the development of a stair-climbing wheelchair mechanism with high single step capability. The mechanism is based on front and rear wheel clusters connected to the base (chair) via powered linkages so as to permit both autonomous stair ascent and descent in the forward direction, and high single step functionality for such as direct entry to and from a van. Primary considerations were inherent stability, provision of a mechanism that is physically no larger than a standard powered wheelchair, aesthetics and being based on readily available low cost components.
\end{abstract}

Index Terms - stair-climbing, wheelchair, wheel cluster operation, high single step, barrier present environments.

\section{INTRODUCTION}

$\mathrm{T}$ he primary general purpose mobility assistance device to date for the mobility impaired has been the wheelchair. For the outdoor environment the mobility scooter has become increasingly popular. The choice of wheelchair is based on the user's physical and mental ability.

A common approach to negotiating stairs is shown in Fig. 1 , carrying the person in a lightweight wheelchair, one or two persons at each side. An alternative common approach is carrying elderly or disabled persons on one's back. While this represents a very efficient approach it also presents risk of injury for both persons [1].

The choice of a manually propelled wheelchair while providing essential exercise of remaining physical abilities is largely limited to "barrier free environments," that is, environments that do not impede access to such devices as wheelchairs. The inherent high COG (center of gravity) of lightweight wheelchairs combined with reliance on user propulsion makes them unsuitable to steep slopes $\left(\sim>5^{\circ}\right)$, rough surfaces and of course stairs. Lightweight wheelchairs and users can however be assisted up or down stairs with 2 to 4 assistants.

The powered wheelchair in comparison has a much lower COG due to significant battery and motor weight low to the ground making them better suited to slopes and rough surfaced areas. However the aspect of stairs and entrance to a secondary means of transport, typically a van, represent significant difficulties.

Manuscript received May 27, 2002; revised March 2, 2003.

M. J. Lawn is with the Department of English and Computer Science at Nagasaki Junshin Catholic University, Nagasaki 852-8558, Japan (phone/fax: ++81-957-22-8382; email murraylawn@bigfoot.com).

T. Ishimatsu is with the Department of Mechanical Engineering, Nagasaki University, Nagasaki 852-8521, Japan (e-mail: ishi@net.nagasaki-u.ac.jp).

Digital Object Identifier 10.1109/TNSRE.2003.816875

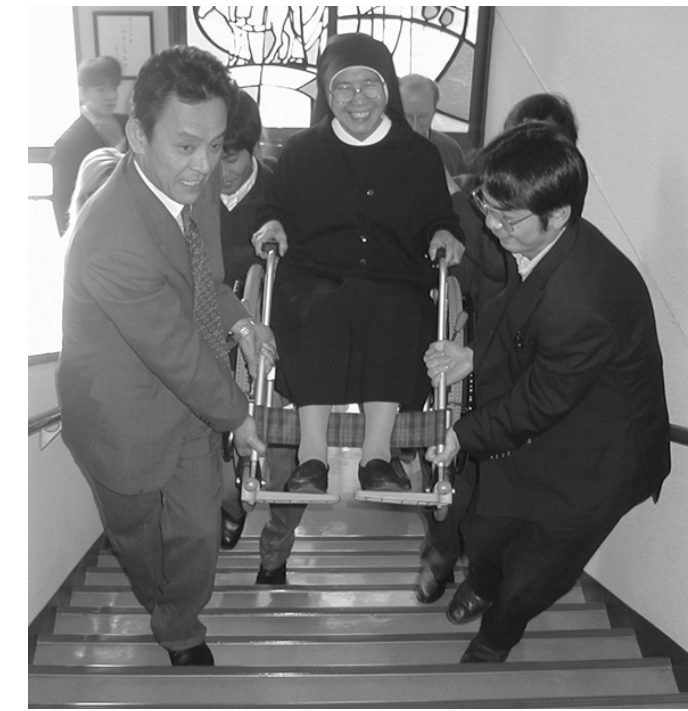

Fig. 1. Stair-climbing - current common technique

Table 1 provides a broad categorization of stair capable mobility enhancement wheelchairs and devices available at the time of writing.

This paper focuses on presenting a mechanism optimized for wheelchair use and targeted at overcoming a number of shortcomings in currently available wheelchairs with regard to operation in barrier present environments. Specifically the high single step functionality necessary to directly board such as a van without the need for any special lifting equipment, and the ability to autonomously ascend and descend stairs in the forward direction. Other functionality and physical dimensions are equal to that of a standard powered wheelchair.

\section{II.BACKGROUND}

The last 100 years or so have seen many technological advances, however with regard to mobility assistance only minor changes have occurred with regard to the basic wheelchair. The first commercially available stair-climbing wheelchair based on a single section track mechanism became available in the mid 90's (in Japan). Single track mechanisms are also available with a simple platform on which a manual or powered wheelchair and occupant can be carried up or down stairs [2] and [3]. This approach is used at some railway stations in Japan where elevators are not available. A single section track stair-climbing wheelchair was used by Nagasaki University for assistance in transporting elderly and disabled persons in the Hillside areas of Nagasaki. However complaints from persons being transported led to the development of a two stage tracked 
TABLE I

BROAD CATEGORIZATION OF STAIR CAPABLE MOBILITY ASSISTANCE DEVICES

\begin{tabular}{|c|c|c|}
\hline Device & Advantages & Disadvantages \\
\hline Stair chair lift & $\begin{array}{l}\text { Compact, suits } \\
\text { narrow stairways }\end{array}$ & $\begin{array}{l}\text { Requires transfer to and from } \\
\text { such as wheelchair, } \\
\text { mechanism dedicated to } \\
\text { single stairway, expensive. }\end{array}$ \\
\hline $\begin{array}{l}\text { Platform stair } \\
\text { lift }\end{array}$ & $\begin{array}{l}\text { Compact (when } \\
\text { not in use), carries } \\
\text { wheelchair } \\
\text { directly }\end{array}$ & $\begin{array}{l}\text { Requires wide stairway, } \\
\text { mechanism dedicated to } \\
\text { single stairway, expensive. }\end{array}$ \\
\hline $\begin{array}{l}\text { Tracked } \\
\text { stair-climbing } \\
\text { wheelchair }\end{array}$ & $\begin{array}{l}\text { Autonomous } \\
\text { operation on } \\
\text { stairs, slopes and } \\
\text { irregular terrain. }\end{array}$ & $\begin{array}{l}\text { Usually not well suited to } \\
\text { general purpose use, must } \\
\text { ascend stairs in reverse, } \\
\text { special provision required for } \\
\text { entry to van. }\end{array}$ \\
\hline $\begin{array}{l}\text { Lightweight } \\
\text { manual } \\
\text { wheelchair with } \\
\text { stair-climbing } \\
\text { attachment } \\
\end{array}$ & $\begin{array}{l}\text { Same as for } \\
\text { manual wheelchair } \\
\text { plus stair-climbing } \\
\text { ability (with } \\
\text { assistance). } \\
\end{array}$ & $\begin{array}{l}\text { Requires assistance with } \\
\text { stairs and sloped areas (one } \\
\text { person). Special training for } \\
\text { assistant usually required. }\end{array}$ \\
\hline $\begin{array}{l}\text { Powered single } \\
\text { cluster } \\
\text { stair-climber }\end{array}$ & $\begin{array}{l}\text { Excellent overall } \\
\text { mobility in most } \\
\text { environments } \\
\text { including stairs } \\
\text { (with assistance). }\end{array}$ & $\begin{array}{l}\text { Special provision required for } \\
\text { entry to van. Requires } \\
\text { assistance with stairs (one } \\
\text { person). }\end{array}$ \\
\hline $\begin{array}{l}\text { Powered single } \\
\text { cluster } \\
\text { (balancing) } \\
\text { stair-climber }\end{array}$ & $\begin{array}{l}\text { Autonomous } \\
\text { operation on } \\
\text { stairs, slopes and } \\
\text { irregular terrain. }\end{array}$ & $\begin{array}{l}\text { Special provision required for } \\
\text { entry to van. Requires } \\
\text { assistance with stairs (one } \\
\text { person) if appropriate hand } \\
\text { rail/s not provided, must } \\
\text { ascend stairs in reverse. }\end{array}$ \\
\hline $\begin{array}{l}\text { Powered dual } \\
\text { cluster } \\
\text { stair-climber } \\
\text { (articulated }\end{array}$ & $\begin{array}{l}\text { Autonomous } \\
\text { operation on } \\
\text { stairs. }\end{array}$ & $\begin{array}{l}\text { Special provision required for } \\
\text { entry to van. Wider than } \\
\text { standard wheelchairs, must } \\
\text { ascend stairs in reverse. }\end{array}$ \\
\hline
\end{tabular}

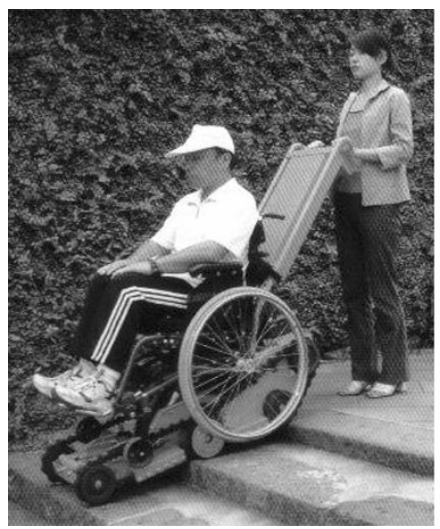

(a)

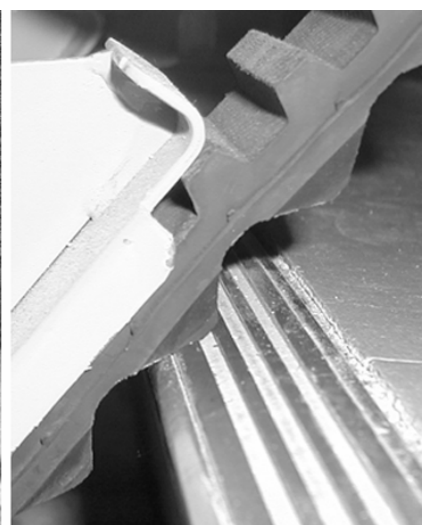

(b)
Fig. 2 (a) The Nagasaki stair-climber KSC-C-10 (b) close up of stair edge Sunwa CDM-2

mechanism at Nagasaki University in conjunction with local industry, in [4], [5] and depicted in Fig. 2(a).

The advantage of tracked operation is simple control and robustness in regard to operation on the roughly hewn, irregular (random), twisting and non-horizontally orientated stairs typically found in older (historic) hillside residential areas, such as those common in Nagasaki (Japan) and many other cities built in mountainous areas worldwide. However inherent problems associated with tracked operation include the high pressure exerted on the edge of the stair being negotiated.
Fig. 2(b) shows a close-up of a tracked stair-climber in contact with a stair edge. Asynchronism between the knobs on the tracks and the stair edges result in the weight being borne by a single stair edge, in the case shown this calculates to a total static weight of approximately $160 \mathrm{Kg}$ (wheelchair plus passenger - StairChair CDM-2) resting on $50 \mathrm{~mm}$ (track width) x 2 (No. of tracks) by $\sim 5 \mathrm{~mm}$ (depth of stair-edge contact), a resulting $32 \mathrm{Kg} / \mathrm{cm}^{2}$. Dynamic considerations exceed this value by magnitudes depending on operator skill and the random nature of knobs slipping due to stair edge asynchronism. This pressure thus limits tracked stair-climbers to stairs with robust edges.

A broad list of stair mobility assistance devices is provided in Table 1 and an outline of respective advantages and disadvantages. Examples of the chair lift are [6], platform lift [7], single section tracked stair-climbing wheelchair [8], dual tracked [9], lightweight wheelchair with stair-climbing attachment [10], powered single cluster stair-climber [11], balancing type single cluster stair-climber [12], and powered dual cluster stair-climber (articulated front wheels) [13]. While the use of purely articulated legs is possible the level of control complexity required to achieve smooth operation is very high [14]. A hybrid approach of using articulated wheels in the form of clusters of wheels is becoming an increasingly common approach to negotiating obstacles such as stairs - as noted in the bottom 4 items in Table 1.

Wheel clusters in their simplest form adapt the most common means of transportation, "the wheel," to the most common obstacle to the wheel, "the stair." If a single wheel cluster is used, a balancing mechanism is required for any form of stair-climbing. In this paper a "single wheel cluster" refers to the lateral configuration of 2 identical wheel clusters. In the case of the simple single cluster stair-climbing wheelchair the balancing mechanism is a human assistant. In the case of a wheelchair with CM (COG modification) an appropriately located hand-rail can be used by the operator (user) to provide guidance signals for the balancing mechanism.

In order to eliminate the need for an assistant or special equipment such as handrails, the mechanism must maintain 4 points of contact with the stairs and be configured in such a way as to provide acceptable stability margins at all times. Three points of contact are possible but difficult considering acceptable stability margins. To achieve this a means of adapting the inherent height differential front to rear that occurs on a typical stair to maintain level chair orientation is required.

With reference to Table 1, two points of lack are noted, firstly no wheelchair mechanism caters for high steps and secondly all autonomous stair-climbers climb stairs in reverse. High steps commonly occur when use of a secondary mode of transportation is required, this is often a van, in the case of Japan the first step to traditional Japanese homes ranges between $30 \mathrm{~cm}$ to $60 \mathrm{~cm}$ in height. Regarding reverse operation, clearly operation in the direction of travel is desirable in providing a simpler and more logical mode of control.

The remainder of this paper outlines a mechanism targeted at providing autonomous operation in the forward direction 
on stairs, as well as providing autonomy in the negotiation of a single high step such as that encountered when entrance to such as a van is required.

\section{Methods}

\section{A. Design objectives}

Central in the design of any mobility assistive device must be safety. Therefore in order to suit the widest possible variety of environments a mechanism that maintains 4 points of contact with the ground at all times was considered essential [15].

Being "easy to operate" is essential for the targeted user group (mobility impaired - disabled or elderly), and will be central in regard to acceptability. In this case proposed operation in barrier free areas is identical to that of a standard powered wheelchair, however by necessity in the negotiation of obstacles such as stairs some low level assistance is required, for example providing the user with such options as vehicle alight, disembark, stair negotiate, additional traction or simply "stand" (high shelf or eye level contact with a standing person).

The aspect of maximizing autonomy is the primary motivation behind this mechanism, that is minimizing the need for reliance on external assistance or special equipment. Thus operation in the forward direction at all times was considered important. This objective has not entirely been met in that although unassisted stair ascent and descent in the forward direction is possible, disembarking from such as a van is only possible in reverse. While the operation can be automated with the assistance of appropriate sensors, clearly a visual check of the planned disembarkation area is essential.

The next objective is a mechanism that does not exceed the physical dimensions of existing technology, in this case the powered wheelchair. This is achieved in the basic design but slightly exceeded in width in the working scale prototype. This was due to the use of mechanical components that were not available in an appropriate scale.

The $3^{\text {rd }}$ objective was a design based on readily available relatively low cost components. This has been achieved due to the recent availability of low cost lightweight high power linear actuators [16].

The final objective ideal is not to exceed the weight of existing technology. This cannot be practically achieved in that addition of almost any functionality will incur additional weight, certainly in the case of early work in such fields. The main reason for concern regarding the weight of such as powered wheelchairs is the man-handling necessary in the presence of obstacles such as stairs or vehicle boarding.

The aspect of maximizing range of operation is inherently related to vehicle weight mentioned above, and additional powered functionality (actuators) also increases loading on the power supply (batteries), further resulting in reduced range of operation compared to a standard powered wheelchair, all other things being equal.

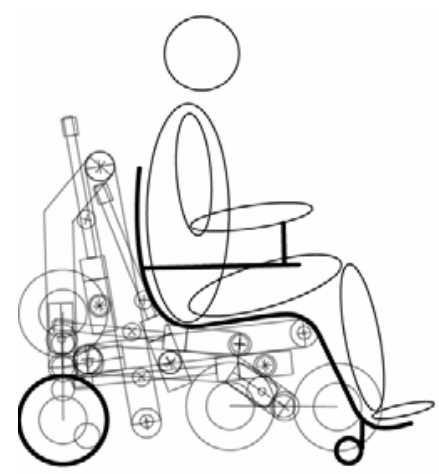

(a)

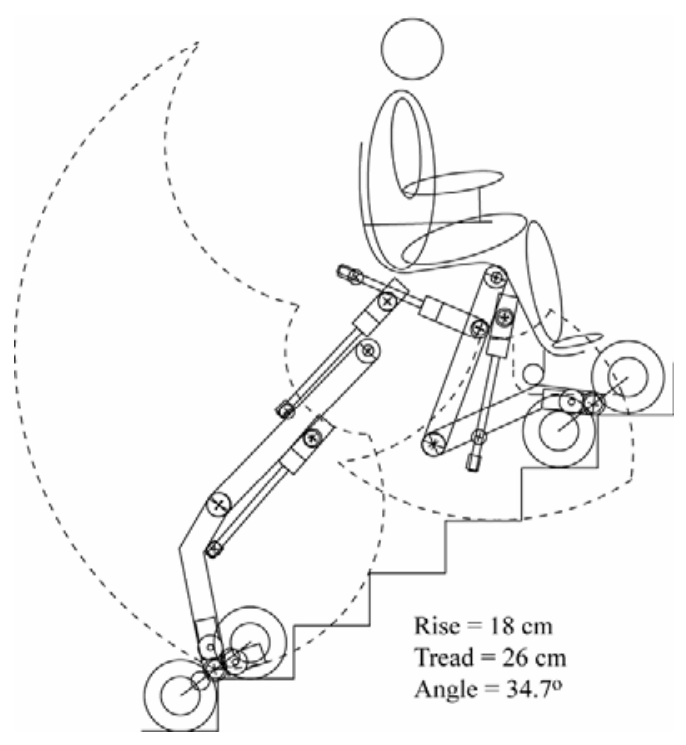

(b)

Fig. 3 The high step stair-climbing mechanism. (a) barrier free mode. (b) Stair-climbing mode

A final consideration is that of aesthetics, or more specifically public acceptance. This aspect cannot necessarily be tied to any logic except to minimize divergence from current (accepted) forms, in this case the power wheelchair. This is achieved to some degree with regard to barrier free operation. However during stair negotiation the mechanism does alter significantly in form and may be perceived as a little too robotic.

\section{B. Outline of design}

A side elevation of the high step capable mechanism is shown in Fig. 3(a) in "barrier free mode," that is operation as a standard powered wheelchair and stair-climb mode is illustrated in Fig. 3(b). Target specifications for the mechanism are listed in Table 2.

\section{Modeling process}

Initially a calibrated 2D (two dimensional) articulated paper model was created and checked for basic kinematics. The design was then numerically modeled to allow for the calculation of such as linear actuator output requirements. A controllable model based on a 1 to 6.25 scale was built to confirm basic mechanical feasibility and to some extent controllability. The scale model used $4 \mathrm{~cm}$ pneumatic tires and miniature RC servos. The leg design was based on that 
TABLE II

HIGH STEP STAIR-CLIMBING MECHANISM TARGET SPECIFICATIONS

\begin{tabular}{|c|c|}
\hline Item & Specification \\
\hline Max. continuous stair-climb angle & $35^{\circ}$ standard $\left(45^{\circ}-\max ^{* 1}\right)$ \\
\hline Maximum step height & $200 \mathrm{~mm}$ \\
\hline Minimum step tread & $200 \mathrm{~mm}$ \\
\hline High single step & $750 \mathrm{~mm}^{* 2}$ \\
\hline Maximum slope angle & $25^{\circ * *^{3}}$ \\
\hline Stair-climb speed (max.) & 20 steps per min. $(1 \mathrm{step} / 3 \mathrm{sec} .)^{* 4}$ \\
\hline Stair descent speed (max.) & 20 steps per min. $(1 \mathrm{step} / 3 \mathrm{sec} .)^{* 4}$ \\
\hline Speed on the flat (max) & $8 \mathrm{~km} / \mathrm{h}$ \\
\hline Operating range (time) & \\
\hline $\begin{array}{l}\text { Barrier free operation } \\
\text { Stair operation }\end{array}$ & $\begin{array}{l}140 \text { minutes continuous operation } \\
50 \text { minutes continuous operation }\end{array}$ \\
\hline Size length, width, height & $1,150 *^{5} \times 550 \times 900 \mathrm{~mm}$ \\
\hline Seat height & \\
\hline $\begin{array}{l}\text { Barrier free operation } \\
\text { Stand mode (max) }\end{array}$ & $\begin{array}{c}450 \mathrm{~mm} \\
1250 \mathrm{~mm}^{* 6}\end{array}$ \\
\hline Power source (battery) & $12 \mathrm{~V} 35 \mathrm{Ah} \times 2$ \\
\hline Drive motors (primary drive) & 24VDC 208W x2 \\
\hline Vehicle plus battery weight & $130 \mathrm{Kg}+30 \mathrm{Kg}=160 \mathrm{Kg}$ \\
\hline Max. passenger weight & $80 \mathrm{Kg}$ \\
\hline
\end{tabular}

*1 Any angle over $35^{\circ}$ will be reflected in the seat angle, that is the seat angle is normally set at a $-6^{\circ}$ (backward) lean, worst case a $45^{\circ}$ stair would result in $\mathrm{a}-16^{\circ}$ (backward) lean for ascent and $+4^{\circ}$ (forward) lean for descent.

*2 High single step 750mm, in the case of a high single step the landing must provide at least $1,000 \mathrm{~mm}$ of landing space. In the case of the high step including a regular final step as is the case in many Japanese entrances the final step must not exceed $200 \mathrm{~mm}$ in height or $450 \mathrm{~mm}$ in depth.

*3 Under ideal tractive conditions, derating required in case of wet and/ or slippery conditions. Seat angle remains constant, assumes use of barrier present mode.

*4 Assumes synchronous operation.

*5 Vehicle length assumes footplates are folded down, this reduces to $1,000 \mathrm{~mm}$ when the foot plates are folded up.

*6 Level surface assumed for maximum standing height.

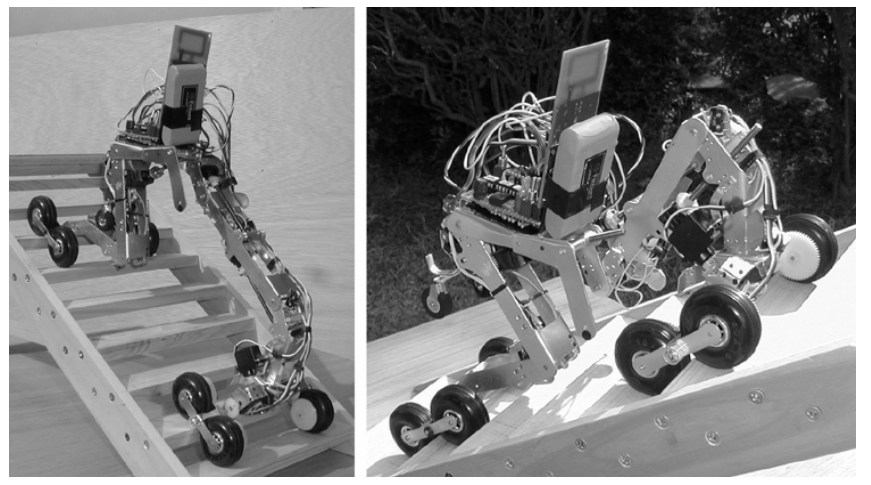

Fig. 4 Stair climb operation. (left) ascent. (right) descent

initially presented in [17], with the addition of the wheel clusters to overcome the need for precise balancing.

The 2D numerical model and scale model achieved the 8 basic phases of operation, which were as follows:

1) entry to a stair-climb

2) stair-climbing

3) stair-climb to a landing

4) entry to stair-descent

5) descending stairs

6) stair-descent to a landing

7) boarding a vehicle (high step)

8) disembarking from a vehicle (high step)

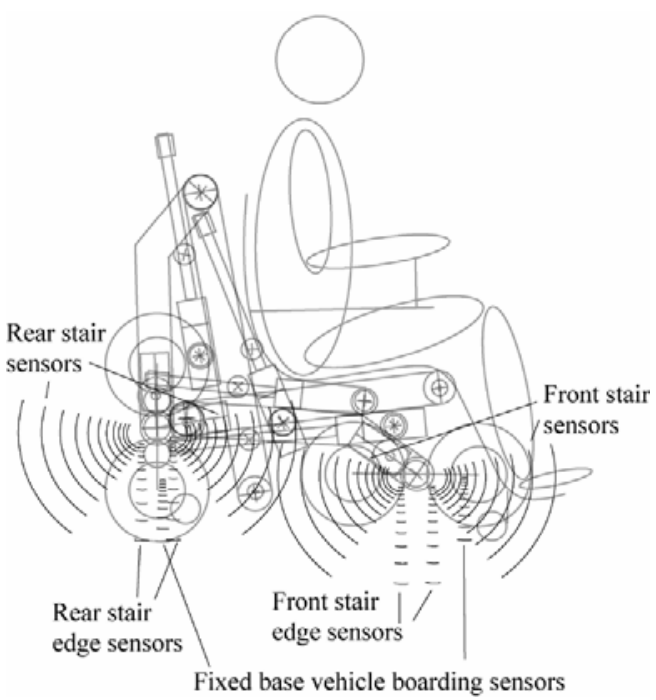

Fig. 5 Proposed stair sensor placement

\section{D.Stair-climbing operation}

Stair negotiation is shown in Fig. 4 and achieved as follows:

1) User indicates "stair-negotiate."

2) The chair is raised sufficiently to permit front mechanism stepping, step and step edge sensors are proposed - refer to Fig. 5. One sensor system to detect a step, indicating need for stair ascent, and another to detect having crossed over the edge of a step, indicating stair descend.

3) The chair continues to rise in a level manner until sufficient height is available to negotiate the next step up or down.

4) The front cluster will rotate up or down at a speed defined by the user, i.e. forward or backward on the joystick.

5) The wheel cluster rotation stops when the wheel cluster returns to a horizontal disposition.

6) The vehicle moves forward, again at a speed defined by the joystick until another step up or down is sensed.

7) The above steps 3 to 6 repeat until the rear cluster mechanism senses a step.

8) When the rear mechanism senses a step if the relative distance between front and rear steps falls between a set range (which varies based mainly on height differential, i.e. stair angle) the front and rear wheel clusters climb synchronously.

9) If the above is not so, front and rear clusters will operate asynchronously (some pitching motion), in this case a small amount of leg actuation is required to compensate for the asynchronous front and rear unit forward movement requirements.

10)Steps 3 to 6 repeat for both front and rear mechanisms until the top or bottom of the stairs is reached.

11)The front mechanism detects no step and remains at a horizontal orientation.

12)The rear mechanism continues operation to the top or bottom of the stair.

13)A horizontal sensor on the chair base provides the necessary control signals to the leg (articulation mechanism) actuators to ensure that the chair angle remains constant at all times. 

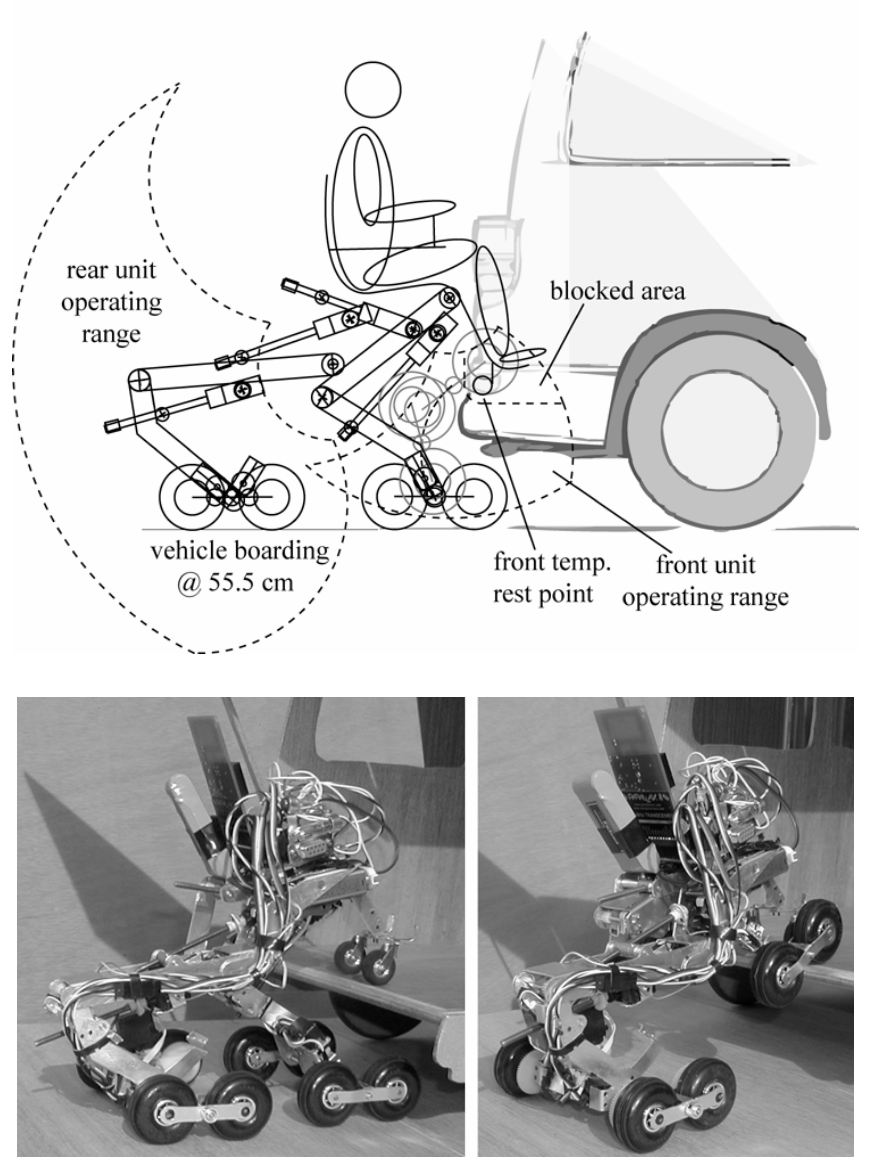

Fig. 6 Direct van entry - rear cluster boarding operation

14)Upon completion of the stair ascent or descent the rear cluster will also remain in a horizontal orientation.

15) Return to barrier free mode can then be selected at which point the rear cluster will change to a vertical orientation and both front and rear leg units fully retract.

During the stair climb and descent the front cluster acts as the master in terms of defining the base (chair) to stair height/ clearance. The chair level is automatically maintained at a $-6^{\circ}$ camber. Fig. 4a shows the mechanism during stair-climbing operation, and Fig. 4b during stair descent in the case of synchronous front and rear cluster operation.

\section{E. High-step operation}

High step negotiation is illustrated in Figs. 6 and 7. High steps are commonly encountered when the need to use some form of secondary transportation occurs. This is often a van.

High single step negotiation is achieved as follows (up):

1) User indicates high step (up).

2) The chair is raised to the appropriate height under user control.

3) The chair is then moved into the position shown in Figs. 6a and 6b. An appropriate sensor is proposed to confirm 3.1 the distance into the high step - refer to Fig. 5.

4) The front mechanism is then folded while being rotated clockwise as shown in Fig. 6a in the path indicated. The front cluster is moved into the position pictured in Fig. 6c.
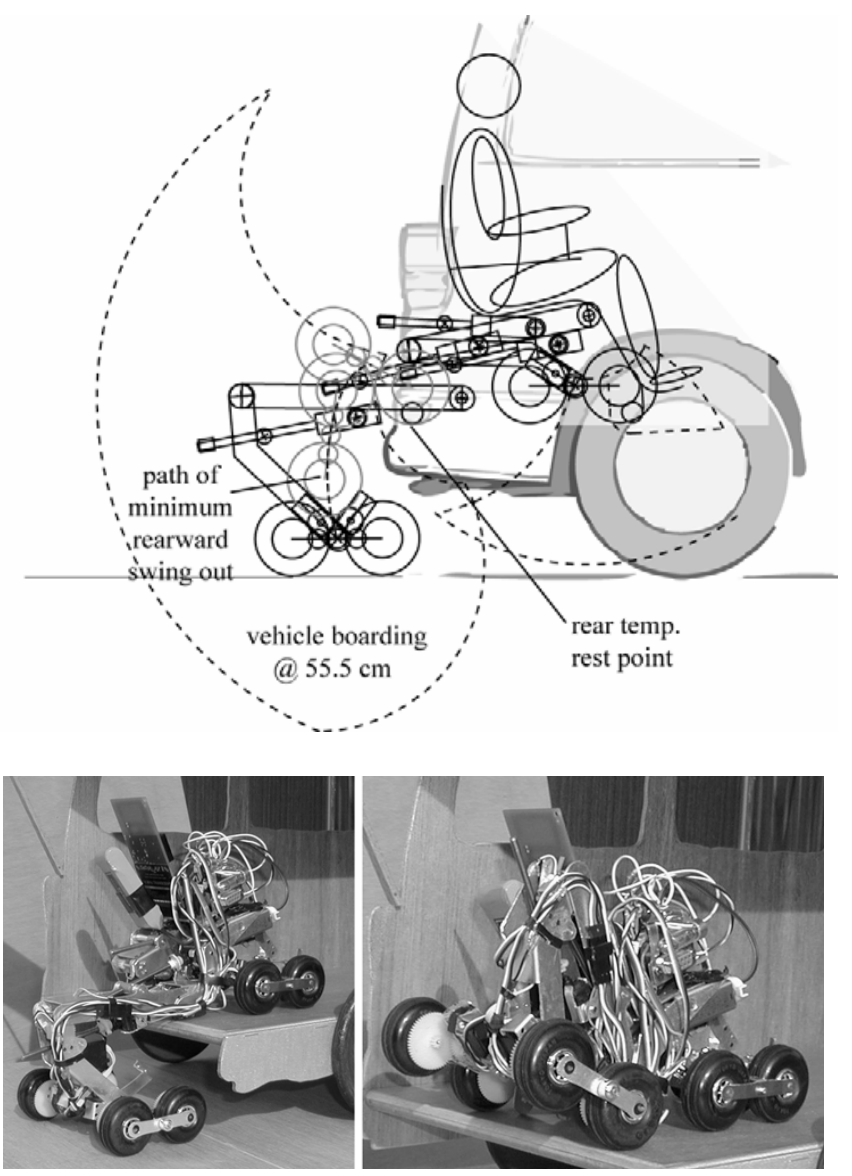

Fig. 7 Direct van entry - rear cluster boarding operation

5) The front wheel cluster continues to a horizontal disposition and lowered to a level a little below the casters thus taking the main weight so as to ensure precise forward movement. This is mainly to prevent any direction changes that may occur on account of van decks which usually are not perfect level surfaces, or to account for the vehicle being parked non-horizontally (free wheeling caster operation under these conditions tends to be erratic).

6) The chair is then moved forward, again under user control, to a position ensuring the temporary rest point shown in Fig. 7a is sufficiently inside the vehicle. This rest point is obscured in Fig. 7b by the wiring but clearly seen in Figs. 4a and 4b. An appropriate sensor is proposed to confirm the rear section distance into the high step - refer to Fig. 5.

7) The rear mechanism is then folded in the manner shown in Fig. 7a, to the position pictured in Fig. 7c. The rear wheel cluster is rotated clockwise as shown in an arc close to the step. The rear wheel cluster represents a significant percentage of the vehicle's weight, therefore unnecessary swing out reduces the overall stability margin in the rearward direction.

8) The rear wheel cluster is then vertically oriented, resulting in the weight and traction being returned to the rear wheel cluster.

9) Finally the vehicle can be relocated in the van and the wheelchair tied down appropriately. 


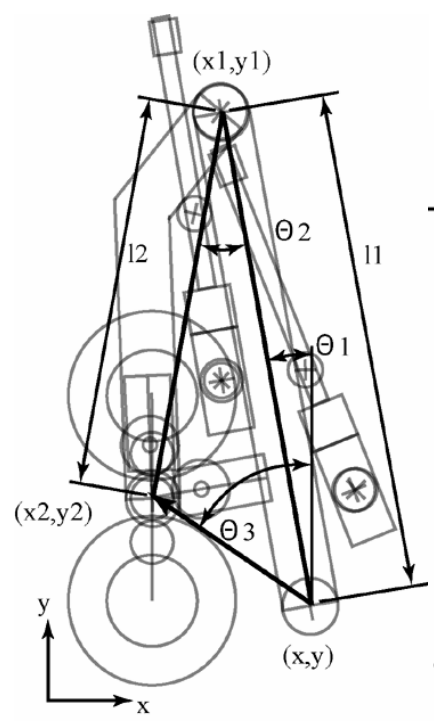

(a)

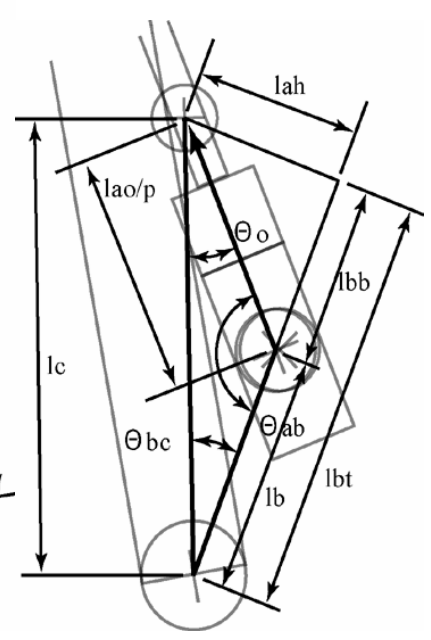

(b)
Fig. 8 Calculation of linear actuator output. (a) output to the wheel cluster . (b) actuator output to the leg (rear upper)

\section{F. Model actuators - power calculations}

The high step mechanism uses 8 RC servos (Futaba S3103). All 8 servo motors were modified for continuous rotary operation. The linear actuators were modeled based on recent availability of low cost, lightweight linear power actuators (Max. 6000N, 5mm/sec no load, 3mm/sec max. load, $24 \mathrm{v}$, weight $2.5 \mathrm{~kg}$, duty cycle $10 \%$ ). The low duty cycle $(10 \%)$ is acceptable in that the linear power cylinders are only required when changing climb phases, for example barrier free mode to stair-climb mode. In the case of continuous or intermittent stair-climb or descent, only the wheel cluster rotation motors and wheel drive motors are required. Linear actuator operation is only required when the average stair pitch changes, and/or in the case of front-rear cluster non-synchronous operation.

Initial papers [18], [19] were written based on the use of hydraulic cylinders powered by a single hydraulic pump.

Calculation of the output power required by the linear actuators is made with reference to Fig. 8. The linear actuator output requirements have been calculated in two basic stages. Firstly, the actuator torque applied to the respective leg as a function of leg angle is calculated, a fixed lifting value is then assumed and the required actuator output power is then calculated based on the kinematics of the upper and lower linkages with regard to vertical. In order to simplify the calculation as far as possible the output is assumed at the center of the wheel cluster, and all mechanical losses, friction etc. are neglected.

The position of $\left(x_{2}, y_{2}\right)$ shown in Fig. 8a. is calculated as follows:

$$
\begin{aligned}
& x_{2}=\ell_{1} \operatorname{Sin} \Theta_{1}+\ell_{2} \operatorname{Sin}\left(\Theta_{2}-\Theta_{1}\right) \\
& y_{2}=\ell_{1} \operatorname{Cos} \Theta_{1}-\ell_{2} \operatorname{Cos}\left(\Theta_{2}-\Theta_{1}\right) \\
& \Theta_{3}=\operatorname{Tan}^{-1}\left(y_{2} / x_{2}\right) \\
& \ell 3=y_{2} / \operatorname{Sin} \Theta_{3}
\end{aligned}
$$

\begin{tabular}{|c|c|c|c|c|}
\hline Description & Notation & Measure & $\begin{array}{c}\text { Operating range } \\
\text { (angle) }\end{array}$ & $\begin{array}{r}\text { Offset } \\
\text { (angle) }\end{array}$ \\
\hline Wheel radius & $r$ & $12.5 \mathrm{~cm}$ & & \\
\hline $\begin{array}{l}\text { Cluster } \\
\text { spacing }\end{array}$ & $d$ & $30 \mathrm{~cm}$ & & \\
\hline $\begin{array}{l}\text { Rear leg upper } \\
\text { link }\end{array}$ & $\ell_{1}$ & $74.5 \mathrm{~cm}$ & $126^{\circ}$ & $\begin{array}{c}10^{\circ} \\
\left(\mathrm{U}=0^{\circ}\right)\end{array}$ \\
\hline $\begin{array}{l}\text { Rear leg lower } \\
\text { link } \\
\end{array}$ & $\ell_{2}$ & $58.4 \mathrm{~cm}$ & $126^{\circ}$ & $\begin{array}{c}22^{\circ} \\
\left(\mathrm{L}=0^{\circ}\right)\end{array}$ \\
\hline $\begin{array}{c}\text { Front leg } \\
\text { upper link }\end{array}$ & $\ell 4$ & $62.4 \mathrm{~cm}$ & $76^{\circ}$ & $\begin{array}{l}96.5^{\circ} \\
\left(\mathrm{U}=0^{\circ}\right)\end{array}$ \\
\hline $\begin{array}{l}\text { Front leg } \\
\text { lower link }\end{array}$ & $\ell 5$ & $57.7 \mathrm{~cm}$ & $70^{\circ}$ & $\begin{array}{c}21^{\circ} \\
\left(\mathrm{L}=0^{\circ}\right) \\
\end{array}$ \\
\hline $\begin{array}{l}\text { Front to rear } \\
\text { Reference }\end{array}$ & $\begin{array}{c}(x, y) \text { rear } \\
\left(x_{4}, y_{4}\right) \text { front }\end{array}$ & $52.2 \mathrm{~cm}$ & $\begin{array}{l}\text { (assumes chair } \\
@-6^{\circ} \text { angle, on } \\
\text { level surface) }\end{array}$ & $61^{\circ}$ \\
\hline
\end{tabular}

TABLE III

HIGH STEP STAIR-CLIMBING MECHANISM GEOMETRIC PARAMETERS

All $\Theta$ values consist of a leg angle value “ $U$ ” for Upper leg angle and "L" for lower leg value and an offset component which relates the leg angle to a vertical reference in the case of the upper leg and to alignment with the upper leg in the case of the lower leg. $U$ and $L=0^{\circ}$ indicates the leg's fully retracted position, while $\mathrm{U}=126^{\circ}$ and $\mathrm{L}=126^{\circ}$ represents the maximum extension values (angles) in the case of the rear leg upper and lower sections. Offset values and lengths relating to equations 1-4 are shown in Table 3.

The output torque applied in this case to the rear leg (upper) can be related to actuator output illustrated in Fig. 8b, and can be calculated as follows:

$$
\begin{aligned}
\ell a h & =\ell_{c} \operatorname{Sin} \Theta b c \\
\ell b t & =\ell_{c} \operatorname{Cos} \Theta b c \\
\ell b b & =\ell_{b t}-\ell_{b}
\end{aligned}
$$

The actuator output position $\ell a o / p$ is thus given by

$$
\begin{aligned}
& \ell a o / p=\sqrt{\ell b b^{2}+\ell a h^{2}} \\
& \Theta_{a b}=180-\operatorname{Cos}^{-1}(\ell b b / \ell a o / p)
\end{aligned}
$$

The actuator's angle of incidence $\Theta_{0}$ to the leg is given by

$\Theta_{0}=180-\Theta b c-\Theta a b$

The torque at $\left(x_{1}, y_{1}\right)$ denoted $T\left(x_{1}, y_{1}\right)$ can be calculated from

$$
T(x 1, y 1)=P_{0} \ell c / \ell_{1} \operatorname{Sin} \Theta 0
$$

(1) where $P_{0}$ is the actuator's mechanical output power

(2) $(\mathrm{kgf} / \mathrm{cm})$. The resultant lifting capability to the wheel cluster (3) center can be expressed as

(4) $P_{\text {lift }}=P_{0} \ell_{c} \operatorname{Sin} \Theta_{0} / \ell_{3} \operatorname{Cos} \Theta_{3}$ 


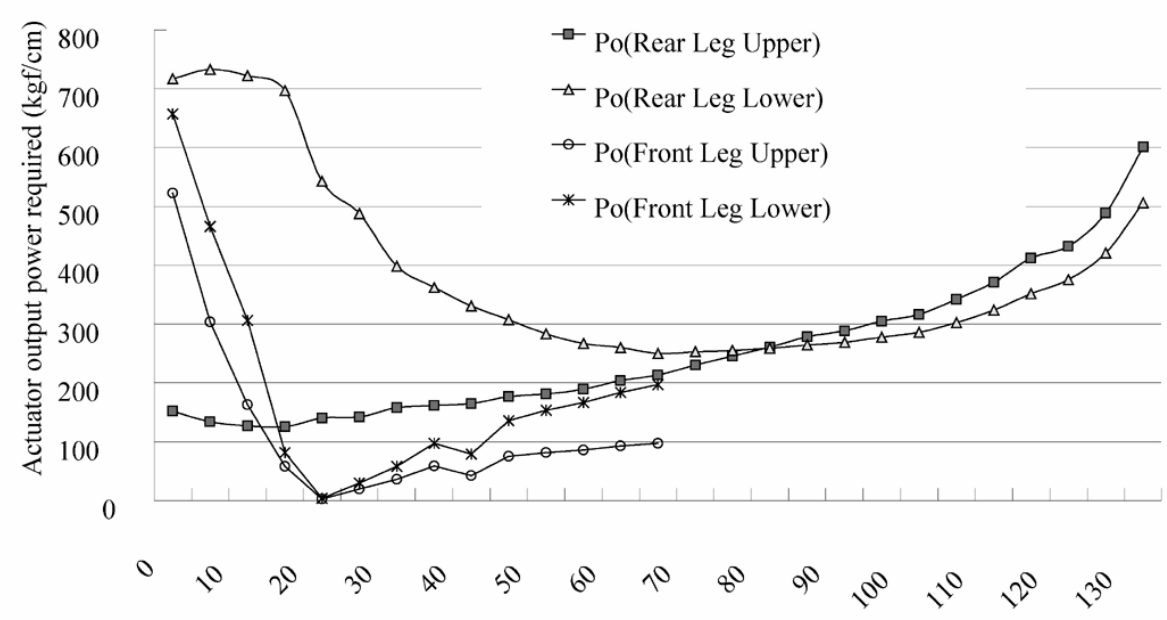

Front/ Rear leg extension $(\mathrm{cm}) 0=$ barrier free mode

Fig. 9 Required linear actuator power outputs vs. respective wheel cluster extensions (leg extending at $78^{\circ}$ outwards with respect to horizontal)

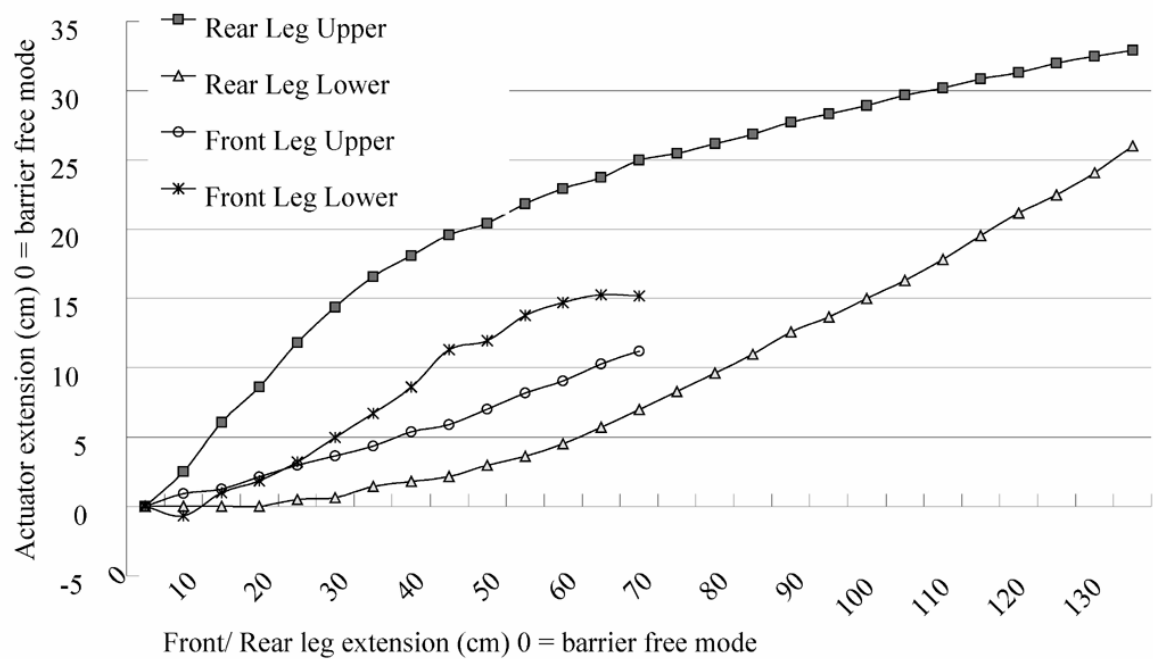

Fig. 10 Actuator extension vs. respective wheel cluster extensions (leg extending at $78^{\circ}$ outwards with respect to horizontal)

where $P_{\text {lift }}$ represents the resultant vertical lift component at the wheel cluster center. As the lift component is fixed in this case $80 \mathrm{Kg}$ (detailed in the section on stability margins) the expression is rearranged to give the required actuator output power for any given configuration of the legs. This is expressed as

$$
P_{0}=P_{\text {lift }} \ell_{3} \operatorname{Cos} \Theta_{3} / \ell_{c} \operatorname{Sin} \Theta_{0}
$$

In applying this to the lower actuator the expression is altered to

$$
P_{0}=P_{\text {lift }} \ell_{2} \operatorname{Cos}\left(\Theta_{2}-\Theta_{1}\right) / \ell_{c} \operatorname{Sin} \Theta_{0}
$$

where $\ell_{c}$ and $\Theta_{0}$ refer to the lower actuator's parameters.

Fig. 9 shows the calculated actuator output requirements for each actuator. This data is based on the front and rear wheel clusters following a near linear trajectory from a barrier free orientation to the rear leg orientation shown in Fig. 11 and front leg orientation shown in Fig. 12. The leg angle data was measured from the calibrated 2D paper model and then calculations made as per formulae (1) to (14).
The kinematic orientation of each actuator was optimized based on five main constraints. Firstly a peak output of 600 $\mathrm{kgf} / \mathrm{cm}(\sim 6000 \mathrm{~N})$ was assumed. Secondary, the overall size of the wheelchair must not exceed that of a standard powered wheelchair. The seat height (in barrier free mode) must match that provided by a standard wheelchair $(\sim 45 \mathrm{~cm})$. The front and rear leg operating envelope must facilitate negotiating a $36^{\circ}$ set of stairs forward up and forward down with no change in chair angle and finally be able to negotiate a single step e.g. vehicle entry of up to $75 \mathrm{~cm}$ (forward up - back out).

With reference to Fig. 9 the peak output appears to be exceeded at 2 points. Firstly, the rear leg lower actuator exceeds the $600 \mathrm{kgf} / \mathrm{cm}$ for the first $20 \mathrm{cms}$ of operation, however with reference to Fig. 10 which shows "actuator extension," operation is not required during this phase. In the case of the front leg upper cylinder the first $5 \mathrm{~cm}$ of operation simply lowers the front wheel cluster to the ground in order to take over from the free wheeling casters, therefore no output power is required during this phase. Peak outputs only occur during the first few seconds of reconfiguration from barrier free mode and at maximum reach in the case of the rear mechanism. 


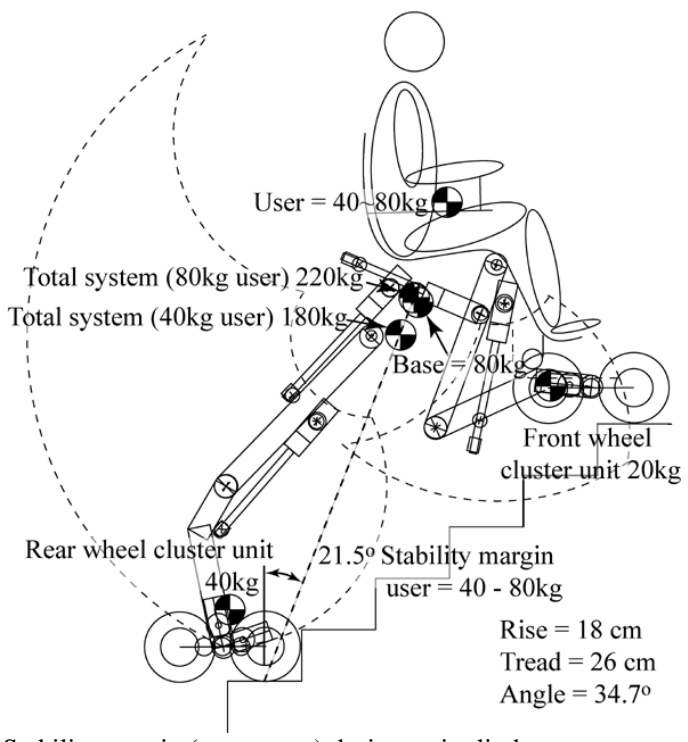

Fig. 11 Stability margin (worst case) during stair climb

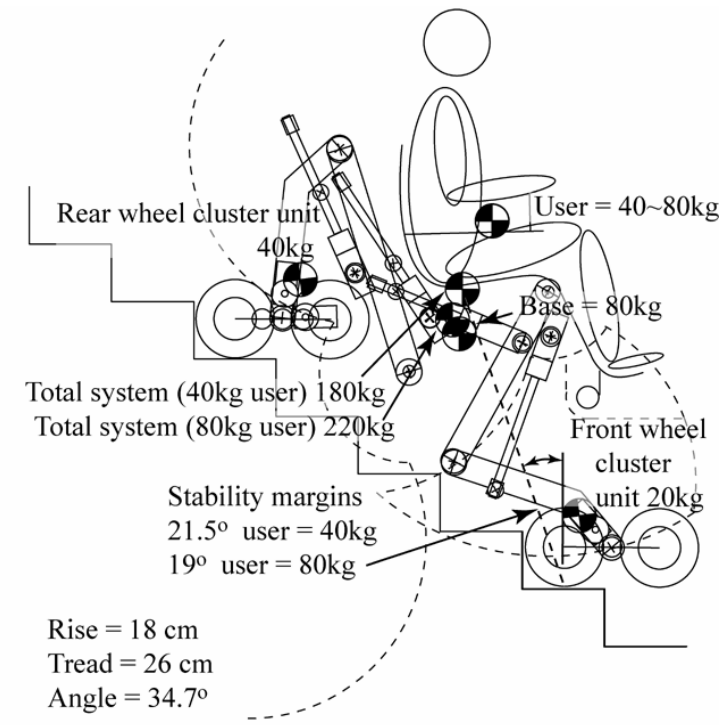

Fig. 12 Stability margin (worst case) during stair descent

\section{G.Stability margins}

In the design of any assistive device, safety is central. Figs. 11 and 12 show worst case stability analysis with regard to stair ascent and descent respectively. The analysis is based on assumed lumped centers of mass as shown. A user weight of 40 to $80 \mathrm{~kg}$ is considered. The effect of reconfiguration of the upper legs and cylinders is not considered significant compared with the wheel cluster units. Each linear cylinder $\sim 2.5 \mathrm{~kg}$ in weight moves over a range of less than $10 \%$ compared with the wheel clusters and are therefore lumped together with the base. The chair base weight consists mainly of $2 \times 15 \mathrm{~kg}$ standard powered wheelchair batteries which are located in diagonal opposition, one under the front of the right hand side of the chair and the other to the rear on the left hand side (referenced to the user's orientation).

In the case of the stair climb the user's COG (center of gravity) is aligned with that of the overall system COG, and therefore stability is constant irrespective of the user's weight. Stability during the descent phase is more complex, in order to maximize the stability and minimize the user's "perceived concern” regarding the slightly impeded view of terra firma, it is essential to keep the chair base as low as possible. The main constraint in this regard is clearance between the front leg central joint and the stairs, as seen in Fig. 12.

During the descent phase the user's COG is not aligned with that of the overall system and the stability margin reduces from $21.5^{\circ}$ for a $40 \mathrm{~kg}$ user to $19^{\circ}$ for an $80 \mathrm{~kg}$ user. The stability margins involved in vehicle boarding are less critical than stair negotiation, as can be seen in Figs. 6 and 7. The location of the wheel clusters, particularly the rear wheel cluster can be altered freely (within operating envelopes) to facilitate a stability margin of $>25^{\circ}$ for the maximum high step operation $(75 \mathrm{~cm})$.

The wheelchair control system clearly must monitor the stability margins at all times during barrier present operation. In the case of stair negotiation one parameter cannot easily be ascertained, that is which wheel pair is the load bearing pair at any given time. Knowledge of such however is not necessary if the innermost pair (with respect to the chair base) is assumed to be load bearing thus giving the worst case stability margins. The above stability margins are static only considerations, and assume the wheel cluster rotation acceleration is not significant. With regard to the user's position (COG) in the case of stair-climbing, the user is not liable to relocate themselves to the rear of the chair, however in the descent condition the user's repositioning their weight to the front edge of the chair would negatively impact the stability margin.

\section{H. Wheel cluster trace}

Fig. 14 shows a detailed wheel cluster trace based on "rotation to level", that is the cluster upon sensing a step will rotate until the cluster returns to a horizontal orientation. Once level orientation is achieved forward motion returns to user control and sensing of a next step (if present) becomes valid.

This simple “one step at a time” algorithm assumes no regularity in the steps. In the case of stair descent reference is made to falling edge detection. Synchronism between the front and rear wheel clusters depends on stair spacing. The front and rear units operate independently except that drive is provided by the rear wheels and therefore the front cluster operates as slave to the rear cluster in regard to forward or reverse operation. In this regard when the front wheel cluster senses a step it requires the motion shown by the "wheel cluster center trace." The $\mathrm{z}$ value can be approximated as follows:

$$
z=\sqrt{d^{2}-h^{2}}-r
$$

with reference to Fig. 14. The representative modeled parameters are provided in Table 3 . Regarding the d value, keeping this value as small as possible provides maximum step edge clearance and provides for optimal power transmission ability (i.e. max. sprocket/ gear size) for wheel cluster unit rotation. Ideally the cluster's wheels should be located as close as possible e.g. $\mathrm{d}=2 \mathrm{r}+\sim 1 \mathrm{~cm}$, that is $1 \mathrm{~cm}$ clearance between the cluster's wheels. 


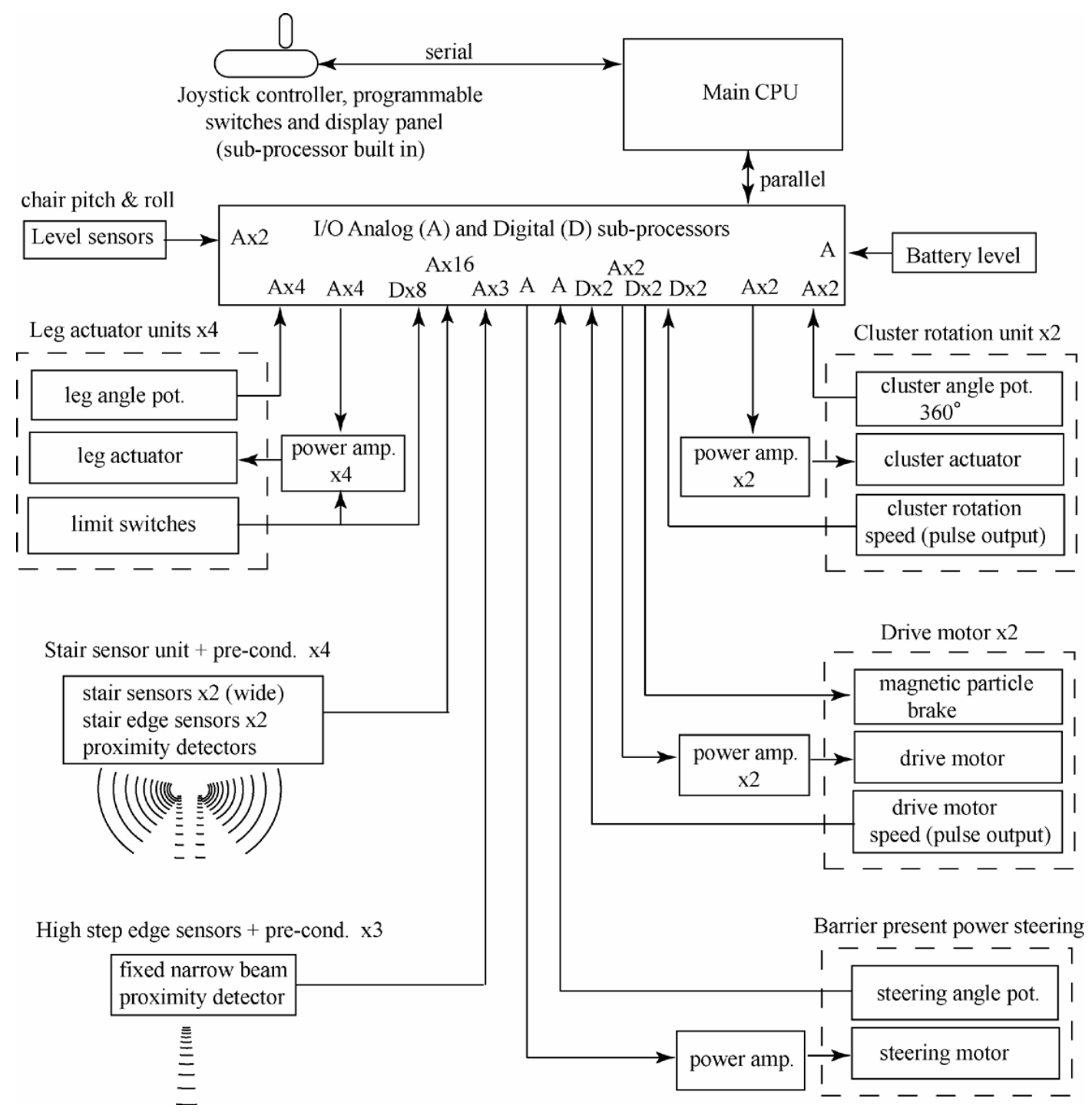

Fig. 13 Control system schematic for proposed high step stair-climbing mechanism

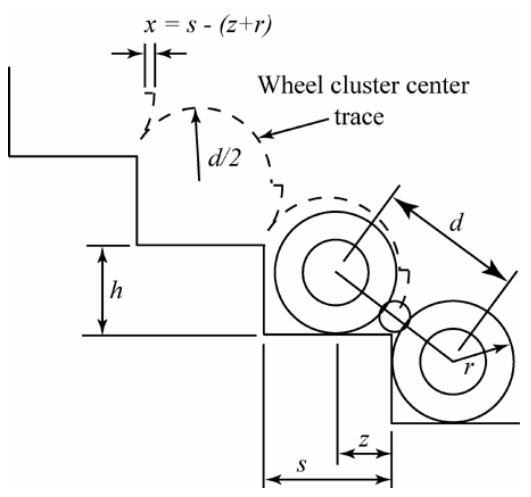

Fig. 14 Wheel cluster trace detail

\section{Control system}

The proposed high step mechanism control system schematic is shown in Fig. 13. A minimum control system based on two single chip computers (BS2) an RC Servo MUX (FT649) and RC servo controllers (FT639) was built to operate the scale model shown in Figs. 4, 6 and 7.

\section{DISCUSSION}

The mechanism presented in this paper does not indicate any provision of steering during stair negotiation. Such functionality (power steering) is however assumed as being provided for in the lower section of the lower front leg mechanism, providing the front wheel cluster with $\pm 45^{\circ}$ of steering. With the addition of steering functionality during stair negotiation the stair sensors need to be duplicated (left and right), in order to assist with the negotiation of laterally irregular tread depths. Spiral staircases are possible providing the step depth does not fall below about 1.5 times the wheel radius, which represents a tread depth of $18.75 \mathrm{~cm}$ in the mechanism modeled (20cm spec. in Table 2).

\section{V.CONCLUSION}

A stair-climbing wheelchair mechanism with high single step capability has been numerically modeled, simulated and a functional scale model built. The scale model mechanism has been equipped with a minimal control system and successfully operated in the negotiation of stairs both up and down in the forward direction. The mechanism has also been successfully operated in boarding and disembarking from a scale model van. 
The design is based on low cost readily available components. An analysis of actuator output requirements has been provided. Future work is required in the development of the stair-climbing steering mechanism, and the production of a full size prototype mechanism.

\section{ACKNOWLEDGMENTS}

The authors also wish to express appreciation to their respective wives and families for encouragement and patience in making this research possible, and to the members of the Nagasaki Hillside Association Group and Aging Society Research Group for their inspiration and assistance.

\section{REFERENCES}

[1] M. Kurihara, S. Ota, Nagasaki Emergency vehicles and rehabilitation from emergence medical services toward local care, Shodosha (in Japanese), 1999.

[2] R. Misawa, Japan Patent 8-286753, Oct. 29, 1996

[3] R. Misawa, US Patent 6,158,536, Dec. 12, 2000.

[4] T. Ishimatsu, K. Sugiyama, M. Kurihara, "Development of a stairclimbing machine in Nagasaki," Proc. $3^{\text {rd }}$ International. workshop of Advanced Mechatronics, Kanwon, Korea, pp.214-217, 1999.

[5] M. Lawn, T. Sakai, M. Kuroiwa, T. Ishimatsu, "Development and practical application of a stairclimbing wheelchair in Nagasaki," Journal of HWRS-ERC, Int. Journal of Human-friendly Welfare Robotic Systems, pp. 33-39, 2001.

[6] Eliminating stairway barriers, Max-Ability Inc., (2002, Sept 24), [Online]. Available: http://www.sonic.net/jtfig/maxability/stair-lift2.html

[7] Stair lift platforms, Garventa Accessability, (2002, Nov 22), [Online]. http://www.garaventa.ca/sl/index.html

[8] Stair-Chair SC-1 (earlier version CDM-2), Sunwa Ltd.,571 Negishi, Sayama-shi, Saitama-ken, Japan 350-1325.

[9] KSC-A-11 \& KSC-B-10, Kyowa Elect. Industry Corp., 10-2 Kawaguchi-cho, Nagasaki, Japan 852-8108.

[10] Scalamobile, Ulrich Alber GmbH + Co. KG, Sigmaringer Str. 100, D-72458, Albstadt, Germany.

[11] RH-2001A, , (2002, May 20). [Online]. Available (in Chinese only): http://www.runsoft.com.cn/fwzx/fwzx4(wtjd).htm

[12] D. Kamen, R. Ambrogi, R. Heinzmann. US Patent 5,975,225, Nov. 2, 1999.

[13] Tomo Co. Ltd, Tamagawa University. (2002, May 20). Freedom. [Online]. Available (in Japanese only): http://www.tomo-co.co.jp/free.htm

[14] S. Hirose, K. Yoneda; "Toward Development of Practical Quadruped Walking Vehicles,” Journal of Robotics and Mechatronics Vol. 6, pp.498-504, 1993.

[15] P. Wellman, W. Krovi, V. Kuma, W. Harwin, "Design of a Wheelchair with Legs for People with Motor Disabilities," in IEEE Trans. Rehab. Eng., vol. 3, pp. 343-353, 1995.
[16] Hiwin Corp, (2002, May 20). LAH Series linear actuators [Online]. Available: http://www.hiwin.com

[17] M. Lawn, T. Ishimatsu, T. Takeda, "Towards a "Barrier Free" wheelchair," Proc. $16^{\text {th }}$ IMEKO World Congress, Vienna, Austria, vol 7, pp. 63-67, 2000.

[18] M. Lawn, "A robotic hybrid wheelchair for operation in the real world," in Computer Science Center, Nagasaki Institute of Applied Science, No. 8, pp. 65-77, 1997.

[19] M. Lawn, T. Takeda, "Development of a 20 DOF wheelchair for operation in a barrier present environment," Proc. $8^{\text {th }}$ ISMCR Int.l Symp. Measurement and Control in Robotics, Prague, Czech Republic, pp. 411-416, 1998

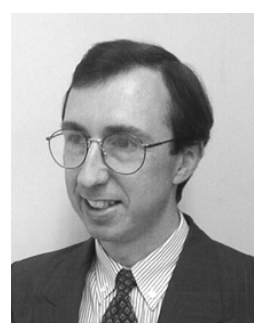

Murray J. Lawn (M'88) received a degree in electrical engineering at Canterbury University, New Zealand in 1989, and a PhD in mechanical engineering at Nagasaki University Japan in March 2003.

He worked as a technician and later engineer for the New Zealand Railways, then as a communications consultant for NZ Telecom. In 1994 he came to Japan where he teaches computer science at Nagasaki Junshin Catholic University and is a visiting lecturer at the Nagasaki Institute of Applied Science

Dr. Lawn (CEng MIEE, MIEICE) received prefectural awards for innovation (stair-climbing wheelchair) in 1997 and 1998. Studies and interests include the development of Stair-climbing devices, multimedia in education and the use of Virtual Reality in rehabilitation training.

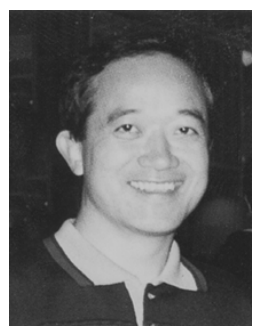

Takakazu Ishimatsu received a degree in engineering at Kyushu University Japan in 1974, Masters degree in 1976 and $\mathrm{PhD}$ in 1979.

In 1980 he became an Assistant professor at Nagasaki University researching computer graphics and robotic assistive devices. He was appointed as Professor of the Mechanical Systems Dept. in 1990. He is currently secretariat to both the Nagasaki Hillside Association and the Aging Society Research Group, and an active member of the Nagasaki Technology promotion committee.

Prof. Ishimatsu's interests include Stair-climbing devices and the prototyping of a wide variety of assistive devices and systems for the aged and disabled. 